\title{
PENGARUH MODEL PEMBELAJARAN READING CONCEPT MAP CONNECTION DISCUSSION EVALUATION (RCCDE) TERHADAP HASIL BELAJAR SISWA
}

\author{
${ }^{1}$ Deri isro'i, ${ }^{2}$ Siti Roudlotul Hikamah, ${ }^{3} \mathrm{Umi}$ Nurjanah \\ ${ }_{123}$ Pendidikan Biologi, Universitas Islam Jember \\ 1disroi44@gmail.com,2sitihikamah@yahoo.com,3kholidumi@yahoo.com
}

\begin{abstract}
ABSTRAK
Penelitian ini bertujuan mengetahui Pengaruh Model Pembelajaran Reading Concept Map Connection Discussion Evaluation (RCCDE) terhadap Hasil Belajar Siswa, dengan sampel penelitian siswa kelas VIII A eksperimen dan kelas VIII B kontrol di SMP Islam kasiyan-puger, dengan teknik Quasi Eksperimen. Analisis data menggunakan uji normalitas dan independen sampels $t$ test. Berdasarkan hasil penelitian diperoleh perbedaan yang signifikan antara kelas eksperimen dan kelas kontrol dalam hasil belajar siswa. Hal ini ditunjukan dengan uji normalitas dengan nilai 0,084 pada pre test dan 0,131 pada post test $>0,05$. Pada uji independen sampels $t$ test dengan nilai 0,030 maka $<0,05$. Sehingga disimpulkan ada pengaruh antara kelas eksperimen dan kelas kontrol yang berarti penggunaan model pembelajaran RCCDE berpengaruh terhadap hasil belajar siswa.
\end{abstract}

kata kunci: model pembelajaran RCCDE, hasil belajar, sistem pencernaan

\begin{abstract}
This study aims to determine the effect of the Reading Concept Map Connection Discussion Evaluation (RCCDE) learning model on student learning outcomes, with the research sample of class VIII A experiment and class VIII B control in Kasiyan-puger Islamic Junior High School, with a Quasi Experimental technique. Data analysis used normality test and independent sample $t$ test. Based on the results of the study. It was found that a significant difference between the experimental class and the control class in student learning outcomes was shown by the normality test with a value of 0.084 in the pre test and 0.131 in the post test $>0.05$. In the independent sample $t$ test with a value of 0.030 then $<0.05$. So it can be concluded that there is an influence between the experimental class and the control class, which means that the use of the RCCDE learning model has an effect on student learning out comes.
\end{abstract}

Keywords : RCCDE learning model, learning outcomes, digestive system

\section{PENDAHULUAN}

Pada proses pembelajaran Kurikulum 2013 yang berpusat kepada siswa (student centered learning) guru hanya sebagai fasilisator dan motivator. Student centered learning (SCL) merupakan suatu proses yang membuat peserta didik menjadi pusat perhatian selama pembelajaran berlangsung. (Nursanti, 2017)

Sekolah mengharapkan ketuntasan hasil belajar siswa diatas nilai minimum dan proses pembelajaran sesuai dengan kurikulum 2013 (Kisa'i, 22 Oktober 2018). UU No. 20 tahun 2003 yang mengatakan bahwa kopetensi kelulusan adalah kualifikasi kemampuan tamatan yang meliputi sikap, pengetahuan dan keterampilan sesuai dengan standar nasional yang ada. Kesenjangan yang ditemukan yaitu kurikulum mengacu pada kurikulum 2013 tetapi belum terlaksananya (student center learning) di SMP Islam Kasiyan Jember-Puger (Laili dkk, 2019).

Hasil wawancara yang dilakukan di SMP Islam Kasiyan-Puger Jember terdapat suatu permasalahan dalam proses pembelajaran IPA. Beberapa permasalahan tersebut yakni rendahnya minat baca siswa serta kurangnya pemahaman siswa dalam memperhatikan 
pelajaran sehingga pembelajaran kurang efektif. Selain itu kurangnya motivasi dari diri sendiri atau dukungan orang tua membuat nilai siswa rendah (Husna, 18 september 2019).

Inti dari membaca ialah merespon simbol-simbol yang tertulis dengan menggunakan makna yang benar dan tepat. Hal tersebut sesuai yang dikatakan (Tarigan, 2008) yang mengartikan membaca ialah suatu proses yang dilakukan dan digunakan oleh pembaca untuk mendapatkan pesan yang ingin penulis sampaikan melalui media kata atau bahasa tertulis. Membaca tidak semudah melafalkan bentuk dan tanda tertulis saja, tetapi juga membutuhkan suatu proses untuk memahami dari bacaan tersebut.

Hasil belajar merupakan hasil yang telah dicapai oleh siswa setelah mengalami proses evaluasi pembelajar berupa angka, sikap, dan keterampilan yang ditentukan dalam beberapa waktu. Hal ini didukung oleh (Dimyati dan Mudjiono, 2002) bahwa hasil belajar merupakan suatu puncak dari proses saat pembelajaran. Hasil pembelajaran ini terutama karena evaluasi dari guru. Hasil evaluasi guru diharapkan dapat mengentahui perubahan tingkat perkembangan mental siswa menjadi lebih baik dari sebelum pembelajaran.

Berdasarkan hasil wawancara dengan guru biologi di sekolah SMP Islam Kasiyan-Puger Jember dikemukakan bahwa kelas VIII A berjumalah 23 siswa dan kelas B22 siswa, masing-masing kelas hanya 15\% mencapai ketuntasan minimal, sedangkan $85 \%$ sisanya belum tuntas,sedangkan nilai ketuntasan minimal (KKM) yang harus dicapai adalah 70. Hal ini sesuai dengan kurikulum di SMP Islam Kasiyan-Puger Jember.

Oleh karena itu, penulis akan melakukan penelitian dengan judul pengaruh model pembelajaran Reading Concept Map Connection Discussion Evaluation (RCCDE) terhadap hasil belajar siswa.

\section{METODE PENELITIAN}

Jenis yang digunakan dalam penelitian ini adalah eksperimen semu (Quasi Eksperimen), karena variabel tidak dapat dikendalikan. Bentuk quasi experimental design yang digunakan adalah desain kelompok kontrol (control group design) the non equivalent posttestonly. Pada control group design, pengambilan sampel baik kelompok eksperimen maupun kelompok kontrol dilakukan dengan teknik pengacakkan yang biasa dilakukan pada desain ini yaitu cluster random sampling atau acak kelas. Teknik kelas dalam populasi yang akan diambil sebagai sampel memiliki karaktaristik yang homogen atau relatif homogen (tidak ada kelas unggulan) (Yudhanegara, 2015).

Variabel yang digunakan dalam penelitian ini merupakan variable independen $(X)$ yaitu Model pembelajaran Reading Concept Map Connection Discussion Evaluasion (RCCDE), dan variable dependen (Y) yaitu Hasil Belajar Siswa Kelas VIII di SMP Islam Kasiyan-Puger Jember.

Populasi yang di ambil dalam penelitian ini adalah siswa SMP Islam Kasiyan-Puger Jember tahun pelajaran 2018/2019. Dalam penelitian ini diambil sampel berupa dua kelas yang berbeda dengan jumlah yang hampir sama, yaitu pada kelas VIII A berjumlah 23 siswa sebagai kelas ekperimen dan kelas VIII B berjumlah 22 siswa sebagai kelas Kontrol.

Pengumpulan data yang sudah diperoleh dalam penelitian ini berupa data nilai post test siswa dan skor hasil analisis pokok uji. Tes dalam format pilihan ganda yang sudah peneliti kemas beserta lembar jawabannya dibagikan kepada siswa. Setelah itu siswa disuruh agar mengerjakan post test yang 
dibagikan maksimal selama 60 menit. Setelah siswa selesai mengerjakan tugas yang diberikan, kemudian buku tes dan lembar jawaban tetap diletakkan di atas meja masing-masing siswa. Tugas yang sudah dikerjakan oleh siswa, kemudian diambil oleh peneliti untuk dikoreksi dan memberikan nilai pada hasil tes siswa yang dilakukan. Setelah selesai mengerjakan tes yang diberikan, siswa diminta mengisi angket yang sudah disiapkan oleh peneliti untuk mengetahui bagaimana respon siswa terhadap pilihan ganda.

Hasil data dalam penelitian ini kemudian di analisis dengan Uji independen sampels $t$ test pada program SPSS versi 16.0. Tujuan dari penggunaan Uji independen sampels $t$ test adalah untuk mengetahui apakah ada pengaruh atau tidak pada hasil belajar siswa antara yang menggunakan model RCCDE dengan menggunakan model konvensional.

\section{PEMBAHASAN}

Perhitungan yang sudah dilakukan menggunakan SPSS terdapat hasil dari uji normalitas, homogenitas, dan Independen Sampels $T$ Test. Tujuan dilakukan uji normalitas agar mengetahui apakah data berdistribusi normal atau tidak. Data yang sudah teruji normal merupakan syarat yang mutlak sebelum melakukan analisis statistik parametrik. Pada pengujian ini menggunakan uji komogorov-smirnov yang di ketahui nilai signifikansi (sig) pada uji komogorovsmirnov > 0,05 maka bisa dikatakan bahwa penelitian berdistribusi normal. Selanjutnya untuk mengetahui data homogen atau tidak maka peneliti menggunakan uji homogenitas. Pada homogenitas diketahui bahwa nila signifikansi adalah 0,745 maka dapat dikatakan data tersebut homogen.

Setelah data tersebut diketahui normal, maka dapat dilanjutkan dengan uji Independen Sampels $T$ Test, uji digunakan untuk megetahui apakah ada pengaruh penggunaan model pembelajaran RCCDE terhadap hasil belajar siswa sehingga dapat dihasilkan sebagai berikut : ada pengaruh model pembelajaran berbasis RCCDE terhadap hasil belajar siswa kelas VIII SMP Islam Kasiyan-Puger, dari perhitungan Independen Sampels $T$ Test diketahui bahwa signifikansi (2-tailed) 0,030. Sementara dasar pengambilan keputusan jika nilai sig. (2-tailed) lebih kecil dari < 0,05 maka terdapat perbedaan yang signifikan. Sebelum dilakukan model pembelajaran RCCDE dan sesudah dilakukan model pembelajaran RCCDE terhadap hasil belajar siswa kelas VIII pada materi sistem pencernaan manusia sehingga dapat disimpulkan bahwa ada pengaruh model pembelajaran berbasis RCCDE terhadap hasil belajar siswa kelas VIII SMP Islam Kasiyan-Puger. Model pembelajaran berbasis RCCDE ini dapat meningkatkan hasil belajar siswa selama pembelajaran berlangsung. Adapun hasil pre test dan post test pada kelas eksperimen dan kelas kontrol adalah sebagai berikut :

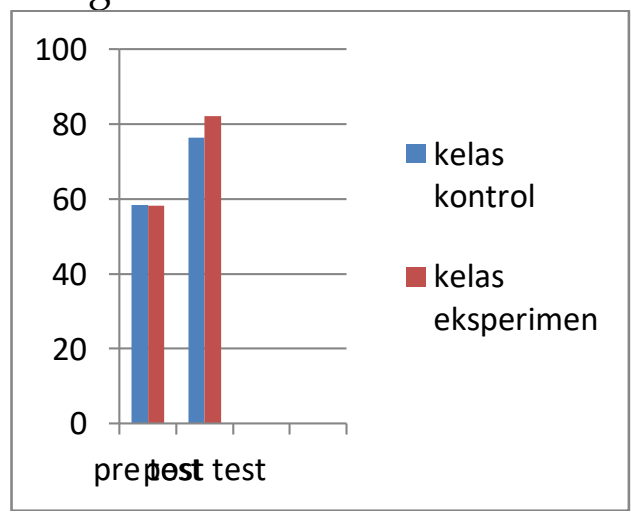

Sumber : data diolah

Gambar 1 Perbandingan nilai rata-rata pre test dan post test pada kelas eksperimen dan kelas kontrol

Berdasarkan hasil yang sudah
didapatkan tersebut maka bisa
disimpulkan bahwa penggunaan model
RCCDE berpengaruh terhadap hasil


belajar siswa, karena siswa dituntut untuk lebih bisa memahami pelajaran dengan caranya sendiri dengan cara membaca materi sebelum pelajaran dimulai, mendengarkan materi yang disampaikan, mengamati gambar yang sudah disediakan peneliti, melakukan kerja sama dengan satu kelompok dan berusaha untuk saling bertukar pendapat. Penggunaan model pembelajaran RCCDE ini memberikan pengaruh yang baik terhadap siswa, karena siswa dapat sering membaca, sesuai yang dikatakatan oleh (Tarigan, 2008) bahwa membaca merupakan proses yang dilakukan serta digunakan oleh pembaca untuk memperoleh pesan, yang inginpenulis sampaikan melalui media tulisan/bahasa.

Penggunaan model pembelajaran RCCDE memberikan beberapa keuntungan yang dapat diperoleh siswa sehingga dapat berpengaruh terhadap hasil belajar siswa khususnya pada materi sistem pencernaan manusia, diantaranya yaitu :

a. Siswa lebih sering membaca.

b. Pembuatan peta konsep sendiri yaitu untuk membuat siswa berfikir secara mandiri.

c. Siswa mampu berpendapat sesuai dengan yang mereka pahami.

d. Siswa dapat berbagi pendapatnya dalam kelompokdan dapat berinteraksi dengan baik, dan mampu bertukar pemikiran atau menghargai pendapat dari kelompok lain.

e. Dan siswa mampu memberi sebuah evaluasi hasil diskusi yang nantinya dapat memperbaiki kedepannya.

\section{KESIMPULAN}

Berdasarkan hasil penelitian dan pembahasan yang sudah peneliti lakukan, bisa dikatakan bahwa ada pengaruh penggunaan model pembelajaran RCCDE pada kelas VIII SMP Islam Kasiyan-puger. Hal ini dapat ditunjukan dengan hasil yang sudah didapatkan dan ada perbedaan antara kelas eksperimen dan kelas kontrol, hal ini ditunjukan dengan hasil uji Independen Sampels T Test, post test kelas eksperimen dan kelas kontrol diperoleh nilai signifikansi (2-tailed) 0,030 sementara dasar pengambilan keputusan jika nilai sig. (2-tailed) lebih kecil dari < 0,05 maka terdapat perbedaan yang signifikan antara kelas eksperimen dan kelas kontrol. Dengan demikian ada pengaruh terhadap penggunaan model pembelajaran RCCDE pada kelas VIII di SMP Islam Kasiyan-puger.

\section{SARAN}

Berdasarkan kesimpulan yang sudah didapat, maka ada saran yang perlu disampaikan sebagai berikut:

a. Setelah mengetahui hasil data yang diperoleh, diharapkan guru dapat menggunakan model pembelajaran RCCDE pada setiap pembelajaran.

b. Siswa sebaiknya dibiasakan membaca materi sebelum pembelajaran dimulai. Karena dengan membaca siswa dapat lebih mudah memahami materi yang akan disampaikan di kelas.

c. Peneliti berikutnya diharapkan mampu untuk dapat mengembangkan hasil penelitian ini lebih baik lagi sehingga penelitian ini dapat menjadi lebih baik lagi dan bermanfaat bagi dunia pendidikan kita saat ini.

\section{DAFTAR PUSTAKA}

Dimyati dan Mudjiono. 2002. Belajar dan pembelajaran. Jakarta: Rineka Cipta dan Depdikbud.

Husna, Sofiyatul. 2019. “Guru mata Pelajaran IPA terpadu SMP Islam 
Kasiyan-Puger" [Wawancara]. 18

September

Karunia, Eka Lestari dan Mokhammad Ridwan Yudhanegara. 2015. Penelitian Pendidikan Matematika. Bandung: PT refika Aditama

Laili, A. F., Hikamah, S. R., Nurjanah, U. 2019. "Pengaruh Model Pembelajaran RCCDE (Reading Concept Map Connection Discussion Evaluation) Terhadap Hasil Belajar Siswa pada Sistem Pernafasan di MTs Al-Hidayah". Jurnal Bioshel Vol. 08 No. 01 2019. Hal 471-476. http://ejurnal.uij.ac.id/index.php /BIO/article/view/671

Nursanti, Eky. 2017. Pengembangan Media Pembelajaran Student Centered Learning Materi Pengaruh Bahan Pengembang Pada Pembuatan Muffin Untuk Mata Pelajaran Produk Cake Di Smk Negeri 4 Yogyakarta. Skripsi, Program Studi Pendidikan Teknik Boga Fakultas Teknik Universitas Negeri Yogyakarta.

Tarigan, Henry Guntur. 2008. Membaca sebagai Suatu Keterampilan Berbahasa. Bandung: Angkasa. 